\title{
Sensory attributes of the squash made from bael and pineapple
}

\author{
- S.B. Palve*, N.G. Devshete and T.S. KulKarni \\ Department of Food Engineering, K.K. Wagh College of Food Technology, NASHIK (M.S.) INDIA \\ Email : sbpalve@kkwagh.edu.in; ngdevshte@kkwagh.edu.in and kulkarnit63@yahoo.in \\ *Author for Correspondence \\ Research chronicle : Received : 30.07.2015; Revised : 24.10.2015; Accepted : 26.11.2015
}

SUMMARY:

Sensory attributes of the squash prepared from bael (Aegles marmelos) and pineapple (Ananas comusus ) fruit juices was evaluated. Fruit juices of ripe bael and pineapple fruits were incorporated for the preparation of the squash at different levels where $\mathrm{T}_{0}\left(100 \%\right.$ bael juice), $\mathrm{T}_{1}(75 \%$ bael and $25 \%$ pineapple juice), $\mathrm{T}_{2}$ (70\% bael and $30 \%$ pineapple juice), $\mathrm{T}_{3}(60 \%$ bael and $40 \%$ pineapple juice) and $\mathrm{T}_{4}$ (50\% bael and $50 \%$ pineapple juice). Good quality squash can be prepared by blending 70 per cent bael and 30 per cent pineapple fruit juice $\left(\mathrm{T}_{2}\right)$. Bael and pineapple fruits have good medicinal and nutritional properties like improvement of digestive system, anti- diabetic, pyretic, laxative, antioxidant, etc. It is seen that the organoleptic score of the squash prepared by blending 70 per cent bael and 30 per cent pineapple fruit juice was highest, i.e 7.82, followed by the treatment $\mathrm{T}_{1}, \mathrm{~T}_{3} \mathrm{~T}_{0}$ and $\mathrm{T}_{4}$.

KEY WORDS : Bael, Pineapple, Squash, Sensory

How to cite this paper : Palve, S.B., Devshete, N.G. and Kulkarni, T.S. (2015). Sensory attributes of the squash made from bael and pineapple. Internat. J. Proc. \& Post Harvest Technol., 6 (2) : 162-167. 